uncommon as altogether to escape notice. Every practitioner we believe invariably excludes the air from the syringe before making the injection. Is it supposed that his practice changes when using antitoxin?

A New Anti-tetanus Serum.-The following circular of the New York City Board of Health shows the enterprise and industry of the bacteriologists of that Board:

"The New York City Health Department is prepared to furnish antitoxic serum for the treatment of tetanus. Each vial contains 20 c.c. of serum, having an immunizing power of 1 to $3,000,000$; i.e., 1 c.c. of serum protects $3,000,000$ grams of guinea pigs in weight from a fatal dose of tetanus toxin. The average initial dose of the serum varies with the gravity of the case and the time when treatment is begun. The remedy is administered by deep hypodermic injections, a large syringe (such as has been employed for diphtheria antitoxin) being preferably employed for the purpose, although an ordinary hy podermic syringe carefully cleaned may be used, the barrel of the syringe being repeatedly filled. Some point on the anterior surface of the body should be chosen for the injection, where there is an abundance of subcutaneous cellular tissue, as the anterior surface of the abdomen or thorax or the outer surface of the thigh. Before the remedy is administered the skin should be carefully washed with some disinfecting solution, and the syringe carefully sterilized and then washed with sterilized water. The solution is rapidly absorbed and it is better not to employ massage over the point of injection. It is of vital importance in tetanus that the antitoxin be administered at the earliest possible moment, as the dose required to neutralize the tetanus toxin absorbed increases with great rapidity with each hour's delay. When the treatment is begun at the first appearance of tetanic symptoms and they do not point to a very severe infection, and especially when the incubation period has been long, e.g., two weeks : one vial, or 20 c.c., may suffice for the first injection, and, according to the results, onehalf the quantity or the same quantity should be repeated as intervals of from six to twelve hours during the four following days. If the infection is intense, as shown by a short incubation period, e.g., five to eight days; or by the rapid development of the tetanic symptoms and by the predominance and intensity of bulbar phenomena, or if the treatment is begun several days after the appearance of the tetanic symptoms, even if at the time of injection they are not severe, the contents of one vial should be at once injected, and the dose repeated at short intervals, according to the effect produced on the tetanic symptoms. The doses required where the wound has been previously untreated, even if the symptoms are slight, are usually large. The dose for children under twelve should be one-half or less that for an adult. The use of tetanic antitoxin does not preclude the employment of other remedies, such as chloral, the bromids, physostigmin or morphin. Some one or more of these remedies should be employed in full doses. It is also thought to be advantageous to give large amounts of water to the patient for its diuretic effect, as the tetanus toxin is eliminated by the kidneys. Where tetanus follows some wound of the surface, this should be treated freely with some preparation of iodin in solution, to destroy the toxins in it. The ordinary antiseptic solutions, such as carbolic acid and bichlorid of mercury, are of little value for this purpose. The exact value of tetanus antitoxin in the treatment of this disease and the best method of administration have not been fully determined and the Health Department of the city of New York especially requests that all persons using this preparation of antitoxis serum will forward a full report to the Department of the case and the resuits of treatment. All public institutions in New York City, on application, will be furnished with tetanus antitoxin free of charge.

"Approved by the Board of Health at a meeting held May 19, 1896. Fimmons Ctakk, Sec'y; Charles G. Wilson, Pres.

"Address The Bacteriological Laboratories, Health Department, Criminal Court Building, Center, Elm, White and Franklin Streets. Telephone, 448 Franklin."

Health Reports. - The following health reports have been received in the office of the Supervising Surgeon-General, U. S. Marine-Hospital Service :

$$
\text { SMALLPOX (UNITED STATES). }
$$

Louisiana: New Orleans, May 31 to June 6, 4 cases, 1 deaths. SMALLPOX (FOREIGN).

Birmingham, Eng., May 23 to 30,2 cases.

Bombay, India, April 28 to May 12, 58 deaths.

Buenos Ayres, Brazil, March 1 to 31, 24 deaths.

Calcutta, India, April 25 to May 2, 1 death.
Callao, Peru, May 3 to 17,13 deaths.

Genoa, Italy, May 23 to 30,1 ease.

Guayaquil, Ecuador, May 15 to 30,7 deaths.

Licata, Italy, April 16 to 23,3 deaths.

Madrid, Spain, May 19 to 26,10 deaths.

Naples, Italy, May 23 to 30,4 cases, 1 death.

Odessa, Russia, May 11 to 23,7 cisses, 4 deaths.

Pernambuco, Brazil, A pril 1 to 30,55 deaths.

Prague, A ustria, May 16 to 23, 6 cases.

Rotterdam, Holland, May 23 to 30, 1 case.

Tuxpan, Mexico, May 16 to 23, 3 deaths.

Warsaw, Russia, May 9 to 25,4 deaths.

CHOLERA.

India: Bombay, April 28 to May 12, 31 deaths; Calcutta, April 25 to May 2, 252 deaths.

YELLOW FEVER.

Brazil : Rio de Janeiro, May 2 to 9, 38 deaths; Pernambuco, April 1 to 30,8 deaths.

Buenos Ayres, March 1 to 31, 5 deaths.

Cuba: Havana, May 28 to June 4,9 deaths.

\section{ASSOCIATION NEWS.}

Notice.--Members of the Association desiring to attend the Second Pan-American Medical Congress at Mexico in September, as delegates to that body, will please address the Perma nent Secretary" William B. Atkinson, M.D., 1400 Pine Street, Philadelphia, Pa., for their credentials.

Section on Materia Medica, Pharmacy and Therapeutics. - To the Editor:-Enclosed please find copy of resolutions passed by the Section on Materia Medica, Pharmacy and Therapeutics, American Medical Association, at Atlanta, Ga., May 7, 1896 in regard to a paper on "Anti-Phthisin," read by Dr. Ambler.

Dr. Stewart has written you in regard to it. 1 also enclose the address of Professor Klebs, delivered on the same subject. Yours truly, W. B. HiLl, M.D.

Milwaukee, Wis., June 11, 1896.

The Committee beg to report as follows

That Dr. Klebs disclaims any knowledge that Anti-Phthisin is a proprietary remedy, although he admits having heard that the name was copyrighted in Germany, and that he has heard that application for the same has been made in this country.

We also find that all rights to this remedy have been trans. ferred to Karl yon Ruck, and therefore find that it does come in under the head of proprietary medicines, and respectfully refer the publication of the paper to the Business Committee for their consideration.

Whereas, The American Medical Association's Code of Ethics has declared its opposition to secret remedies and refuses to be used as a body, and through its official organs, to further the interests of any and all patent medicines; and

Whereas, Dr. C. P. Ambler, Associate Medical Director and Laryngologist of the Winyah Sanitarium of Asheville, N. C., representing and defending the Klebs Anti-Phthisin before the Association and also Dr. Karl von Ruck, the controller of this product, has declared before the Section on Materia Medica, Pharmacy and Therapeutics, that it is true that Klebs AntiPhthisin is protected by copyright and that a patent has been applied for both in this country and Germany, to restrict its production for the benefit of the owners of the patent.

Resolved, That a committee of three be appointed to investigate the matter without delay, and report its finding to the proper officers of this Association and in the columns of the Journal of the American Medical Association.

Resolved further, That the Committees on Ethics and Publication and such other committee as the Chairman of the Section may deem fit, shall take cognizance of the matter and take such steps as may be considered necessary to prevent the prostitution of this Association and of its JoURNaL for the advancement of this remedy if found excluded by the rules and laws of medical ethics, and shall publish their finding in said JOLRNAL.

\section{SOCIETY NEWS.}

Chicago Medico-legal Society.-At the last meeting of this Society the following officers were elected to serve for the ensuing year: President, Dr. E. J. Doering ; first vice-president, Dr. Sanger Brown; second vice-president, Dr. A. H. 
Cooke; treasurer, Dr. Jos. Matteson; secretary, Dr. John RidIon, 103 State Street.

Washington State Medical Society. - At the annual meeting of this society held in Tacoma May 19 and 20, Dr. R. L. Thomson, of Spokane, was elected president, and Dr. J. M. Semple, of Medical Lake, Secretary. The next meeting will be held in Spokane, May 1897.

Nebraska State Medical Society. - At the annual meeting the following officers were elected for the ensuing year: President, F. D. Haldeman, Ord ; first vice-president, J. Lue Sutherland, Grand Island; second vice-president, O. Grothan, St. Paul; recordaing secretary, G. H. Simmons, Lincoln; treasurer, W. M. Knapp ; corresponding secretary and librarian, H. B. Lowry, Lincoln. The next annual meeting will be held in Lincoln.

Veterans of Indian Wars. - The latest society with military features is the Society of Veterans of the Indian Wars. Article 3 of the constitution provides that any past or present officer or acting officer, non-commissioned officer or soldier of good moral character and reputation, who has served in the army of the United States during an Indian war, and who has actually been in service in the country occupied by hostile Indians, and whose services terminated honorably and who can furnish suitable certificate as to such services, is entitled to active mem bership. No honorary membership is permitted. Dr. W. T. Parker, Groveland, Mass., will furnish information on this subject to those who desire it.

Association of Life Insurance Medical Directors.--The following are the officers of the Association for 1896-7: President, Edgar Holden, M.D., Newark, N. J. ; first vice-president, H. Cabell Tabb, M.D., Richmond, Va.; second vice-president, J. H. Webb, M.D., Waterloo, Ont. ; secretary, O. H. Rogers, M.D., New York City; treasurer, John W. Brannan, M.D., New York City ; executive committee, Drs. Edward Curtiss, New York City, Abel Huntington, New York City, G. R. Shepherd, Hartford, Conn. and Albert Wood, Worcester, Mass. Dr. J. W. Fisher is chairman of a special committee on collective investigation on accurate statistics on certain kinds of impaired lives and Dr. E. H. Hamill is chairman of a committee on research as to impaired family history.

Mississippi Valley Medical Association.- A meeting of the Executive Committee of this association was held at Atlanta, on May 6 , and the following gentlemen were appointed to deliver addresses: Dr. H. N. Moyer, Chicago, address on medicine; Dr. Horace H. Grant, Louisville, address on surgery ; the indications are that the meeting to be held at St. Paul, on October 20, 21, 22 and 23, will be the largest and most successful in the history of the association. As all the railroads will offer reduced rates for the round trip, an opportunity will be given to visit St. Paul and Minnesota during the most delightful season of the year. H. O. Walker, M.D. Detroit, Mich., president; H. W. Loeb, M.D., 3559 Olive Street, St. Louis, secretary ; C. A. Wheaton, M.D., St. Paul, Minn., chairman committee of arrangements.

The American Medico=Psychological Association.-According to the Boston Medical and Surgical Journal, May 28, the fiftysecond annual meeting of the Association, held in Boston during the last week in May, has been largely attended. An address of welcome was made to the society by Governor Wolcott, and the President, Dr. Richard Dewey, delivered an address on "Our Association and Our Associates." At the afternoon meeting papers were read by Dr. Theodore W. Fisher of Boston, Dr. W. Worcester of Danvers and Dr. Henry $J$. Berkeley of Baltimore. An evening session was held at the Hotel Brunswick, the headquarters of the Association, on which occasion there were given addresses by Dr. R. M. Burke of London, Ont., Dr. Joseph G. Rogers of Logansport,
Ind., and by Dr. E. N. Brush. On Wednesday morning the annual election of officers took place, and in the afternoon the nembers, with ladies, were given a lunch at the McLean Hospital in Waverly. In the evening a reception was given to the members by the Boston Medico-Psychological Society at the University Club.

Concerning Antivivisection.--The American Laryngological Association, in annual session at Pittsburg, Pa., May 15, 1896, by unanimous vote, and by appended signatures of its officers and members of committee, hereby records its most earnest and emphatic protest against such legislation as that proposed by the bill entitled, "A bill for the further prevention of cruelty to animals in the District of Columbia," Senate bili 1552, in so far as this legislation embodies measures intended to control and restrict experimentation upon animals conducted in the government laboratories, the medical schools and other institutions of higher learning in the District of Columbia. In making this protest the Association begs to present to the members of Congress the following considerations: Animal experimentation has proved itself by years of usage, the most important and indispensable method of arriving at conclusions concerning the functions of, and the influences which modify or develop, all living organisms. All the greater advances which have been made in the science and art of medicine in recent years have been based, to a great extent, upon such experiments upon the lower animals, especially as conducted in the laboratories of the Government, and in other scientific institutions. These advances would, in fact, have been im possible without such aid. The untold benefit which mankind has derived, and will continue to receive, from these advances, need not be further detailed than to mention the inestimable boon conferred by the discovery and development of the anti toxin treatment of diphtheria, the inoculation for rabies, the detection for tuberculosis in animals, and the consequent lessening of its spread among human beings. The revolutionizing of surgical practice and the success attending the major operations by the introduction of antiseptic measures have been brought about chiefly through animal experimentation. The benefits derived from these experiments largely go to improve public health and prevent infectious diseases. This fact is often overlooked by the laity. J. H. BRYAN, M.D., Chairman of Committee: William H. Daly, M.D., President; H. L. Swads, M.D., Secretary.

Ontario Medical Association.- This Association met at Windsor Ont., June 3 and 4. President, F. LeM. Grasett, Toronto. The following papers were read: "The Treatment of Puerperal Sepsis," by H. T. Machell, Toronto ; "The Operative Treat ment of Mammary Carcinoma," by W. Burt, Paris ; "The Preservation of the Perineum in Labor," by C. B. Oliver, Ber lin; "Neurasthenia," by E. E. Harvey, Norwich: "Pregnancy Complicated with Retroversion-- a Case," by Alex. Bethune, Seaforth ; "Broncho-pneumonia," by A. E. Harvey, Wyoming "Hemoptysis," by J. M. Cotton, Lambton Mills: "Movable Kidney and Another Way of Anchoring It," by F. B. Wilkin son, Sarnia; "Treatment of Abortion," by G. McKeough, Chatham: "Skin Grafting," by R. Whiteman, Shakespeare "Glioma of the Brain," by A. J. Johnson, Toronto; "Roentgen Photography and Its Application to Medicine and Sur gery, with Exhibition of Apparatus and Demonstration," by Edmund E. King, Toronto; "The Rational Treatment of Typhoid Fever," by J. P. Armour, St. Catherines ; "Treatment of Phthisis," by W. B. Geikie, Toronto: "Phthisis as a Factor in the Causation of Insanity," by E. H. Stafford, Toronto: "Absorbable Ligature in Abdominal Surgery," by M. V. Mann, Buffalo, N. Y.; "Mixed Infection," by J. Caven, Toronto; "Missed Abortion," by F. R. Eccles, London : "The Total Stamping out of Transmittable Diseases," by A. Groves, Fergus. The following officers were elected: President, Dr. John Coventry, Windsor : First Vice-President, Dr. F. R. Eccles, London; Second Vice-President, Dr. Clark, Kingston; Third Vice-President, Dr. H. T. Machell, Toronto; Fourth Vice-President, Dr. J. C. Armour, St. Catharines: General Secretary, Jno. N. E. Brown, Toronto: Assistant Secretary, E. H. Stafford, Toronto : Treasurer, Geo. H. Carveth, Toronto. The next place of meeting is Toronto, Ont. 
Indiana State Medical Society.-The following resolutions were unanimously adopted by the Indiana State Medical Society at Ft. Wayne, May 28, 1896, as presented by Dr. E. L. Larkins of Terre Haute.

Whereas, A bill is now pending before Congress known as Senate Bill No. 1552 entitled "A bill for the further prevention of cruelty to animals in the District of Columbia ;" and

WHEREAS, Such a bill is an unjust reflection upon the human. ity of the members of the most humane and charitable profession in the world, and especially against those engaged in experimental work; and

WHEREAS, The passage of such a bill for the District of Columbia would only serve as a nidus for its spread to other States; therefore, be it

Resolved, That the Indiana State Medical Society hereby indorses the report of the Committee on Vivisection of the A merican Medical Association and adopted by that body at the recent meeting in Atlanta; and be it further

Resolved, That the secretary be and is hereby instructed to immediately furnish each member of Congress from this State (House and Senate) a copy of this preamble and the resolutions, properly signed by the president and secretary under seal of the Society, together with a copy of the above named report, instructing them to oppose the action of the so-called Humane Society of the District of Columbia.

Indianapolis, June 16, 1896.

$$
\text { F. C. Неath, M.D., Secretary. }
$$

\section{BOOK NOTICES.}

A Text-Book of Bacteriology. By George M. Sterniberg, M.D., LL. D., Surgeon General U. S. Army. Illustrated by heliotype and chromo-lithographic plates and 200 engravings. Cl., 8vo, pp. 693. New York: William Wood \& Co. 1896.

This book is really a revision of the well-known Manual by the same author, published in 1892. The author says in the preface: "For the benefit of students of medicine and others who do not care especially for the detailed descriptions of nonpathogenic bacteria and the extensive bibliography contained in the Manual, this Text-Book of Bacteriology is now published. It comprises that portion of the Manual above referred to as printed in large type, revised to include all important additions to our knowledge of the pathogenic bacteria since the original date of publication." This is an honest revision and the reader will have cause to complain of few if any omissions. The same modesty has characterized the author's statements in this work in all matters concerning his own discoveries as in the Manual. With regard to the phagocytic action of the white corpuscles, he thus mentions his own clear priority over Metchnikoff : "Now the theory of phagocytosis assumes that the bacilli are picked up by the leucocytes and destroyed in their interior, and that immunity depends largely upon the power of these phagocytes to capture and destroy living pathogenic bacilli. The writer suggested this as an hypothesis as long ago as 1881, in a paper read before the American Association for the Advancement of Science in the following language : 'It has occurred to me that possibly the white corpuscles may have the office of picking up and digesting bacterial organisms which by any means find their way in to the blood: the propen sity exhibited by the leucocytes for picking up inorganic granules is well known, and that they may be able not only to pick up but to assimilate and so dispose of the bacteria which come in their way does not seem to me very improbable in view of the fact that amebæ, which resemble them so closely, feed upon bacteria and similar organisms.' At a later date (1884) Metchnikoff offered experimental evidence in favor of this view, and the explanation suggested in the above quotation is commonly spoken of as the Metchnikoff theory." He then quotes Metchnikoff extensively as showing the details of phagocytic action and refers to recent contradictory statements as follows, p. 257 : "Numerous experiments have been made during the past two or three years with a view to determining whether pathogenic bacteria are, in fact, destroyed within the leucocytes after being picked up, and different experimenters have arrived at different conclusions. In the case of mouse septicemia, already alluded to, and in gonorrhea, one would be disposed to decide, from the appearance and arrangement of the pathogenic bac teria in the leucocytes, that they are not destroyed, but that on the other hand, they multiply in the interior of these cells, which in the end succumb to this parasitic invasion. In both of the diseases mentioned we find leucocytes so completely filled with the pathogenic microörganisms that it is difficult to believe that they have all been picked up by a voracious phagocyte, which has stuffed itself to repletion, while numerous other leucocytes from the same source, and in the same microscopic field of view, have failed to capture a single bacillus or micrococcus. Moreover, the staining of the parasitic invaders, and the characteristic arrangement of the 'gonococcus' in stained preparations of gonorrheal pus indi cate that their vitality has not been destroyed in the interior of the leucocytes or pus cells, and we can scarcely doubt that the large number found in certain cells is due to multiplication in situ rather than to an unusual activity of these particular cells. . . . We can not consider this question as definitely settled." The author then quotes Metchnikoff's views in full. The Americans may congratulate themselves that the ablest and most comprehensive text-book on bacteriology in the English language has been given to the world by one of their own countrymen. The publisher has done his part of the work with the uniform excellence which is characteristic of the house.

Typhoid Fever and Its Abortive Treatment. Вy Јонм Eutot WoonBRIDGE, M.D. Copyrighted. Cl., 8vo, pp. 368. Price, \$3. Cleveland, Ohio: L. Leavengood \& Company. 1896.

This book is a revision of the various essays of the author, most of which have been published from time to time in this Journal. His "theory" being: 1. Full acceptance of the microbic causation of typhoid fever; 2 , an opinion that the bacilli in question may be destroyed in the body ; 3 , in consequence of that destruction the fever may be aborted or cut short. The means of accomplishing these laudible objects, Dr. Woodbridge thinks is found in the small doses of calomel and other drugs which he specifies. Few statements have met with more vituperative comment than the statement that typhoid fever may be cut short or aborted, and Dr. Woodbridge is not to be blamed if he repels some of the attacks with some heat, although enthusiastic as he is, he must admit that the majority is against his doctrine to-day. Whatever may be urged against Dr. Woodbridge's theories of treatment, all can agree with his notions of prophylaxis, which consist in the application of all known means of securing a good supply of pure drinking water and of preserving that water supply from pollution.

The chapter on diagnosis is an excellent one, and the book as a whole will constitute a valuable addition to the literature of the subject.

Instead of a series of essays, we look to see the work at its next edition grow into a systematic monograph on typhoid fever, for whether the antiseptic treatment of typhoid shall be generally adopted or not, the discussion on symptomatology, etiology and diagnosis will always be of value. The controversial character of the first essays in the volume are bound to attract attention, but in the next edition we trust the author may find it expedient to eliminate all that part of the book.

The Diagnosis and Treatment of the Diseases of the Rectum, Being a Practical Treatise on Fistula, Piles, Fissure and Painful Ulcer, Procidentia, Polypus, Stricture, Cancer, etc. By William Allingham, F.R.C.S., Eng., and Herbert W. Allingham, F.R.C.S., Eng. Sixth edition. Cl., 8vo, pp. 485. New York: William Wood \& Co. 1896

When a book has reached its sixth edition it has passed beyond ordinary criticism. We can only note changes, and satisfy ourselves by reference that recent literature has been 